\title{
Proteção da anastomose brônquica com tecido adiposo autólogo pediculado (Estudo experimental em cães, Canis familiaris)
}

\author{
Bronchial anastomose protection with pedicle autolog fat tissue. An \\ experimental study in dogs, Canis familiaris
}

\author{
Amary Nascimento Junior ${ }^{1}$, Allan Kardec Silveira ${ }^{2}$, Firmino Mársico Filho ${ }^{3}$, Paulo Roberto Loureiro Nascimento ${ }^{4}$, \\ Rogério Tortelly ${ }^{5}$ e José Geraldo Bandoli ${ }^{5}$
}

\begin{abstract}
Resumo
Os autores analisaram 16 cães mestiços, machos e fêmeas, com peso de 12 a 20Kg, hígidos, divididos em dois grupos. Um grupo (II) utilizando um pedículo de gordura mediastinal como tecido autólogo protetor e outro (I) sem proteção da anastomose. Todos os cães foram submetidos a anestesia geral inalatória em circuito valvular com absorção de $\mathrm{CO}_{2}$, mantidos com ventilação controlada manual e a toracotomia lateral esquerda, foi abordada a cavidade pleural através do $5^{\circ}$ espaço intercostal. Com o mínimo de "stripping" peribrônquico seccionou-se a artéria brônquica, procedendo-se em seguida, à secção transversal do brônquio-fonte esquerdo à média distância entre a carina e os lobos. Após a realização da manobra de entubação seletiva foi mantida a ventilação do pulmão direito, até o término da anastomose. O grupo com proteção teve a gordura mediastinal rebatida do pericárdio, mantendo seu pedículo nutridor e fixada em forma de "flap" ao redor da anastomose. Posteriormente foi realizada a toracorrafia por planos e drenagem sub-aquática. Os cães sofreram eutanásia ao $15^{\circ}$ dia de pós-operatório. Os segmentos de brônquios com a anastomose foram submetidos ao exame histológico. Concluiu-se que a desvascularização da anastomose brônquica é um fator de agressão ao processo cicatricial, e que a gordura mediastinal é suficiente para revascularizar a anastomose e promover um processo de cicatrização adequado.
\end{abstract}

Palavras-chave: anastomose, brônquio-canino

\section{Introdução}

O transplante pulmonar teve seus primeiros trabalhos experimentais em cães, iniciados em 1947 pelo fisiologista russo Demikhov e em 1950 pelo cirurgião francês Henry Metras. tendo sua primeira experiência clínica em 1963 por Hary e Webb et al. * (apud Naef, 1988). No Brasil, Araújo, em 1970, descreveu os primeiros problemas técnicos e os resultados acerca do transplante pulmonar unilateral, em um estudo experimental em cães.

Entre 1963 e 1978, nada menos do que 38 pacientes humanos receberam um novo pulmão ou lobo, para tratamento de doenças respiratórias em fase terminal (Deron et al., 1971). As principais causas do malogro clínico, eram rejeição, dificuldade de doadores e os problemas com a cicatrização da anastomose brônquica (Veith, 1978). Mills em um levantamento de 25 transplantes pulmonares em seres humanos até 1970, observou que as complicações brônquicas estavam presentes em treze.

As lesões encontradas com frequência eram caracterizadas por ulceração, estenose e ruptura da anastomose brônquica, causada pela interrupção do fluxo sanguíneo sistêmico, representado no pulmão, pelas artérias brônquicas. O interesse crescente pela cicatrização brônquica, não é recente; Reinhoff 1942 * (apud Normando, 1992) relata que os três principais fatores que levam a uma boa cicatrização brônquica eram: dissecção atraumática, conservação da circulação e sua pleuralização. No Brasil, essa experiência foi iniciada por Figueira de Mello e Siqueira, (1962).

Sabemos que retirando o pulmão viável do doador, inicia-se imediatamente todo um processo isquêmico, além de desnervação, perda dos linfáticos e circulação brônquica e que com isso é alterada a função absorvente, distribuidora e de defesa pulmonar (Cooper et al., 1987, Deffeback et al., 1987). Apesar dos médotos de conservação e perfusão

\footnotetext{
1 Prof. Substituto da Disciplina de Técnica Operatória e Anestesiologia da UFF.

2 Prof. Titular da Disciplina de Técnica Operatória e Anestesiologia da UFF.

3 Prof. Dr. Adjunto da Disciplina de Técnica Operatória e Anestesiologia da UFF.

${ }^{4}$ Prof. Substituto da Disciplina de Técnica Operatória e Anestesiologia da UFF.

5 Profs. da Disciplina de Anatomia Patológica da UFF.
} 
pulmonar, ao se implantar o órgão no paciente recpetor, um dos inconvenientes é a formação de fístulas brônquicas ao nível da anastomose, que no cão ocorre entre o $2^{\circ}$ e $7^{\circ}$ dia de pós-operatório (Normando, 1992).

Estudos recentes comprovam que a proteção da anastomose brônquica por tecidos autólogos pediculados tais como: gordura de grande omento ou pericárdio, oferecem boa revascularização da anastomose brônquica e consequentemente, impedem a formação de fístulas (Lima, 1981; Camargo et al., 1990).

O objetivo do nosso trabalho consiste em estudar experimentalmente, como tecido protetor autólogo pediculado da anastomose brônquica, a gordura mediastinal.

\section{Material e Métodos}

Para este estudo, utilizamos 16 cães (Canis familiaris) escolhidos randomicamente, todos higidos, sem raças definidas, de ambos os sexos, com peso de 12 a 20kg e idades variadas. Todos os animais foram cedidos pelo Instituto Municipal de Medicina Veterinária Jorge Vaitsman.

O grupo I, foi constituído de 8 cães com peso entre 12 e 20kg, nos quais não se usou qualquer tipo de proteção na anastomose.

O grupo II, constituído por 8 cães como peso entre 12 e $18 \mathrm{~kg}$ teve a anastomose protegida com retalho pediculado de gordura mediastinal anterior. Todos os animais receberam cuidados pré e pós-operatório, dentro dos princípios do código de ética experimental com animais formulados pela Sociedade Zoófila Educativa (SOZE) e Associação Protetora dos Animais (A.P.A) do Estado do Rio de Janeiro.

\section{Anestesia}

Os cães foram pré-oxigenados com máscara facial de Hall por 5 minutos, pré-anestesiados com midazolan* $(1,0$ $\mathrm{mg} / \mathrm{kg}$ ) via intravenosa, induzidos com propofol** (3 a $4 \mathrm{mg} /$ $\mathrm{kg}$ ) via intravenosa e a manutenção com halotano*** de 1,0 a 2,0 v\% e 02, através da ventilação controlada manual em um circuito com absorção de $\mathrm{CO}_{2}$. Utilizamos também o brometo de vecurônio**** $(0,1 \mathrm{mg} / \mathrm{kg})$ com bloqueador neuromuscular (Dodman, 1987)

\section{Técnica operatória}

Após os cuidados clássicos de assepsia e antissepsia, iniciou-se o ato cirúrgico com uma toracotomia lateral esquerda, secionando-se os planos musculares com o bisturi elétrico e acessando-se a cavidade pleural através do $5^{\circ}$ espaço intercostal com a diérese da musculatura intercostal realizada na borda cranial do $6^{\circ}$ arco costal. O campo operatório foi isolado com compressas estéreis e introduziu-se o afastador auto estático de Finochieto. Após a verificação da sintopia e ectopia dos órgãos na cavidade torácica, os lobos pulmonares foram afastados em direção ao esterno, utilizando-se uma compressa úmida e evitando-se a compressão cardíaca. Visualizou-se a face dorsal do brônquio fonte esquerdo. Fez-se o mínimo despojamento do tecido peribrônquico e consequente secção da artéria brônquica, seguida da incisão transversal do brônquio, à média distância entre a carina e os lobos pulmonares.

Após a manobra de entubação seletiva* (tubo endotraqueal de duplo lúmen com cuff, 37 - 39 Fr.), foi realizada a anastomose término-terminal com fio ** de poliéster 4-0, (cardiovascular, biagulhado, atraumática) através de sutura contínua (Chuleio simples) em 2 semi-circulos, iniciando-se no ângulo cranial, suturando-se primeiro o semi-círculo ventral e depois o dorsal no sentido horário, onde a sutura pode ser ajustada na porção membranosa do brônquio.

Todo o cuidado com a coptação perfeita das bordas foi tomado, procurando-se o ajuste entre as superfícies mucosas e evitando-se o cavalgamento das cartilagens. $\mathrm{O}$ tempo entre a secção do brônquio e o término da anastomose foi de 15 a 25 minutos. Após a realização da sutura, verificou-se a aeroestasia da mesma através da imersão em soro fisiológico morno e restabelecendo-se a ventilação normal; ao final da manobra aspirou-se todo o soro do interior da cavidade.

O grupo protegido por gordura mediastinal sofreu dissecção da mesma, rebatendo-se por divulção romba do folheto pericárdio e seccionando-se em sua extremidade caudal (próximo ao diafragma), mantendo-se o pediculo nutridor na sua inserção cranial junto à base do coração e tronco-braquiocefálico. O retalho foi conduzido por entre a artéria pulmonar e a veia pulmonar cranial esquerda através da divulção romba do tecido perivascular e pleura mediastinal, fixando-se no tecido peribrônquico ao redor da anastomose com pontos separados simples com fio catgut cromado 2-0***.

Após a realização do "flap" protetor da anastomose e antes da toracorrafia, implantou-se o tubo dreno ao nível do $7^{\circ}$ ou $8^{\circ}$ espaço intercostal na altura da junção costocondral para realização da drenagem torácica com selo subaquático em frasco único, mantido por um ponto incompleto em figura de $U$ até a sua retirada.

A toracorrafia foi realizada mediante aproximação do $6^{\circ}$ arco costal do músculo intercostal com pontos em figuras de $X$ e dos planos restantes com pontos contínuos em chuleio simples.

O sistema de drenagem foi mantido até o paciente voltar à respiração espontânea e após a parada do borbulhamento e a altura da coluna de água exceder $5 \mathrm{~cm}$ em relação à linha d'água, no momento da inspiração. Retirou-se o tubo e completou-se o ponto em figura de $U$.

\section{Pós-operatório}

Nos primeiros 5 dias, todos os animais receberam, além dos cuidados tradicionais, enrofloxacina $(5 \mathrm{mg} / \mathrm{kg})^{\star \star \star \star}$ por
${ }^{*}$ Dormonid - Roche

**Diprivan - ICI ZENECA

$* *$ Fluotane $-\mid \mathrm{Cl}$

****Norcuron - Organon
*Sheridan

** Cirumédica S.A.

${ }^{* * *}$ Cirumédica S.A.

****Flotril 2,5\% Schering-Plough 
via intramuscular. Todos os cães foram sacrificados no $15^{\circ}$ dia de pós-operatório (Strevey, 1970). Na metodologia empregada para a eutanásia, foi utilizado o thionembutal sódico até o coma barbitúrico e logo após o cloreto de potássio a 19,1\% (10ml) também por via intravenosa, conforme preconiza o código de ética experimental com animais de laboratório, formulado pela Sociedade Zoófila Educativa (SOZE) e a Associação Protetora dos Animais (A.P.A)

Para coleta de material, realizou-se a abertura da cavidade torácica com uma incisão em formato de $U$ invertido na parede lateral esquerda do tórax, retirando-se a peça anatômica, que constou de um segmento final da traquéia (região da carina), brônquio-fonte esquerdo e o tecido protetor.

As peças foram acondicionadas em frascos que continham solução de formol tamponado salino a 10\% e enviadas ao laboratório de histopatologia, onde foram submetidas ao processamento de rotina, para coloração por hematoxiina/eosina e ao exame histológico sob microscopia óptica.

\section{Resultados}

Macroscópicos

Todos os cães evoluíram com um quadro clínico favorável durante o período de pós-operatório, a salvo de sinais de infecção, problemas ventilatórios ou, em suma de qualquer complicação cirúrgica.

O pulmão esquerdo, não obstante dos 15 a 25 minutos sem ventilação, não apresentou sinais macroscópicos sugestivos de atelectasia no momento da necrópsia.

Não se observou a presença de fístulas brônquicas, no curso do período pós-operatório em nenhum dos dois grupos.

O traqueotubo utilizado para a ventilação seletiva do pulmão direito facilitou a confecção da anastomose e evitou a agressão cirúrgica ao coto brônquico.

O pedículo de gordura mediastinal foi facilmente obtido e suficiente para envolver a anastomose, apresentando-se como viável por todo o período pós-operatório.

Em todos os cães, a anastomose brônquica encontrava-se totalmente mergulhada na região hilar e envolvida pelo tecido mediastinal e pulmonar. O aspecto macroscópico externo era de normalidade.

No grupo de controle, os cães apresentavam macroscopicamente, na região interna da anastomose, áreas de isquemia, edema, estenose e ulceração.

No grupo com proteção, o aspecto macroscópico da região interna da anastomose era de pequenas áreas de congestão e ligeira estenose.

\section{Microscópicos}

No grupo de controle, o exame microscópico revela processo inflamatório com exsudato misto ao lado da atividade fibroblástica e neoformação vascular. A mucosa se encontra ulcerada, ocorrendo em alguns pontos reação gigantocitária ao fio de sutura.

No grupo com proteção, o exame histológico demonstrou intensa reação inflamatória, principalmente no tecido gorduroso que envolve a sutura brônquica, constituído principalmente por linfócitos, plasmócitos e histiócitos. Verifica- se ainda, neoformação capilar, reação granulomatosa do tipo corpo estranho e atividade fibroblástica.

\section{Discussão}

Após 50 anos do primeiro experimento de transplante pulmonar em cães, as complicações aéreas continuam como as causas importantes da mortalidade nessas operações. Dentre as complicações imediatas, incluem-se deiscência da anastomose, sangramento, infecção e necrose da mucosa. Nas complicações tardias, a fístula artério-brônquica e a estenose brônquica são as mais encontradas, segundo Warren \& Dunphy (1969) e Veith \& Richards (1970).

Diversas e importantes questões técnicas foram discutidas acerca da etiologia dessas complicações relacionadas com as plásticas traqueobrônquicas, no fechamento do coto brônquico pós-ressecção (Faber et al., 1990).

Com respeito ao coto proximal tanto quanto ao distal, a esqueletização realizada durante a dissecção cirúrgica é demasiadamente mutilante para o suprimento sanguíneo da parede brônquica (Rabinovich, 1972). Conseqüentemente, essa situação de isquemia é altamente nociva à cicatrização, predispondo à disjunção da sutura (Strevey, 1970).

O tecido peri-anastomótico é revascularizado apenas pela circulação retógrada do enxerto pulmonar que, na maioria das vezes, se encontra edemaciado e mal acomodado dentro da cavidade torácica, comprometendo o ajuste da anastomose. Outrossim, a circulação pulmonar colateral funciona num regime de baixa pressão, com efeito revascularizante tardio, que acaba por comprometer a circulação (Siegelman et al., 1987).

Em nosso trabalho, encontramos no grupo sem proteção áreas de isquemia, edema, estenose e ulceração da mucosa na área da anastomose. Com efeito, o desponjamento mínimo para a secção do brônquio-fonte, preservando ao máximo o tecido conjunto peribrônquico, não evita a desnervação e tampouco a desvascularização, estando de acordo com Paul et al. (1989), Lo Cicero et al. (1991).

Com a finalidade de evitarmos uma agressão exagerada, realizamos o despojamento mínimo do tecido peribrônquico (Mills et al., 1970, Rabinovich, 1972) e utilizamos o tubo seletivo (Cooper et al., 1987, Alican et al., 1971), que facilita a confecção da anastomose e não leva à formação de microtrombose, como acontece quando são utilizados os clampes brônquicos (Medeiros et al., 1991, Texeira, 1991).

A realização do procedimento técnico cuidadoso, desde a assepsia até o pós-operatório, somado à antibioticoterapia, foi importante para a eliminação de um dos fatores de atuação local, no caso, a infecção. Ora, esta não ocorreu e, assim, não sugerindo complicações comprometedoras da integridade da ventilação pulmonar e da cicatrização (Naruke et al., 1977, Mathiesen \& Grillo, 1991, Bjork, 1956, Fujimura et al, 1987, Virkula \& Aerolas, 1975, Péterffy \& Calabresse, 1979).

A invaginação do brônquio doador para dentro da luz do brônquio receptor é uma técnica inicialmente descrita por Veith et al. (1978). Segundo esses autores, o método produz uma cicatrização brônquica sem problemas, pois que o brônquio seccionado e implantado junto ao mediastino se- 
ria melhor revascularizado pelas estruturas nele contidas. Além do que, o uso do fio monofilamentar de polipropileno produz pouca reação ao nível da mucosa, quando avaliados por broncoscopias no pós-operatório imediato. Faber et al., (1984), diminuíram os índices de granulomas, quando trocaram a sua sutura com seda por sutura com catgute e, posteriormente, por polipropileno. Em nossa experiência, o fio monofilamentar de poliéster, em chuleio simples, mostrou resultados semelhantes aos encontrados por Trummer et al. (1969).

A secção das artérias brônquicas ao nível dos brônquios principais levam à broncopneumonia e à ulceração da parede, enquanto que seu seccionamento ao nível lobar alte-ra a vitalidade do pulmão (Ellis et al., 1951). Por isso, a fim de evitar este processo ulcerativo, já constatado, e na tentativa de melhor cicatrização, seccionamos o brônquio-fonte esquerdo à média distância entre a carina e os lobos (Ellis et al., 1951)

A atelectasia temporária provocada pela suspensão da ventilação não causa problemas ventilatórios no pós-operatório. Tampouco se detectam áreas de atelectasia durante a necrópsia (Araújo, 1970), uma vez que a produção de surfactante retorna a niveis satisfatórios quando se retorna a ventilação do pulmão parado, porém, perfundido (Júdice et al., 1985). Durante a técnica empregada em nosso experimento, o pulmão esquerdo permaneceu parado por 15 a 25 minutos para a realização da anastomose, sem causar problemas de respiração no pós-operatório, não se encontrando áreas de atelectasia durante a necrópsia.

Os métodos de revascularização indireta da anastomose brônquica têm mostrado bons resultados no combate à isquemia pós-transplante. Tornou-se viável, pela facilidade de execução, quando comparada à revascularização direta. Lima (1981), Goldberg et al. (1981), estudando fatores que afetavam a cicatrização brônquica demonstraram que o brônquio envolvido por um pedículo de omento pode ser revascularizado a partir do quarto dia, através de uma rede de microanastomoses formadas entre o pedículo e a microcirculação do brônquio, guiados por fatores de angiogênese. Posteriormente vários autores empregaram outros médotos de revascularização indireta, dentre os quais o retalho de pericárdio com ou sem gordura mediastinal (Brewer et al., 1987, Camargo et al., 1990, Kirk et al., 1990), demonstrando bons resultados experimentais e clínicos. Todavia, uma das complicações desta técnica é sujeitar o paciente à ocorrência de hérnia cardíaca com torção dos vasos da base durante o.pós-operatório. alegaram ainda que esses modelos não necessitam de acesso extratorácico para abordagem do pedículo, por isso levam alguma vantagem. Em nosso modelo experimental usamos apenas o pedículo de gordura mediastinal, sem o retalho de pericárdio, evitando os problemas acima citados e obtendo resultados semelhantes aos de Brewer et al. (1987).

O processo cicatricial encontrado na anastomose parece obdecer a uma regra normal de toda cicatrização (Bogliolo et al., 1972). Onde há escassez na formação do tecido de granulação, provavelmente pelo processo isquêmico, ocorrendo ulceração da mucosa, e estenose
(Normando, 1992), como se observou nos cães do nosso grupo de controle.

No outro grupo experimental com proteção à revascularização indireta parece diminuir a intensidade dessa estenose, porém, necessitamos acompanhar esse processo além do $15^{\circ}$ dia de pós-operatório.

Usualmente, muitos tipos de células são encontrados no epitélio brônquico tais como: células ciliadas, de limpeza, globosas, basais de Kulchitsky e indiferenciadas. Nem sempre é fácil distinguirmos essas células ao microscópio. Assim, dividimos as células do epitélio brônquico canino em duas categorias com base nas formas respectivas: cilíndricas (colunar) e células cubóides. Após o autotransplante, a descamação ou mudanças hiperplásicas das células cilíndricas ou cubóides e descamação das epiteliais foram freqüentemente observadas, exatamente ao redor da anastomose. Linfócitos submucosos variáveis eram quase sempre detectados nessa área. Após o período de pósoperatório, ao exame histológico, o grupo experimental sem proteção apresentou solução de continuidade na mucosa, como encontrado por Fujimura et al. (1987).

A presença da resposta inflamatória, hemorragia, perda da mucosa brônquica, necrose, formação de abcesso e presença de degeneração da cartilagem foram encontradas em graus variados durante a avaliação histológica da anastomose em autotransplantes (Pinsker et al., 1991). Na avaliação histológica do nosso modelo experimental, não foi detectada formação de abcesso, possivelmente em virtude do processo de profilaxia da infecção e antibióticoterapia no pós-operatório.

Assim descremos um método de revascularização indireta na espectativa de observarmos e encontrarmos alguma alteração no processo cicatricial perante a isquemia. Para isso utilizamos um modelo de via aérea que mimetiza perfeitamente a isquemia do brônquio doador no transplante pulmonar unilateral, posto que a secção das artérias brônquicas certamente deixou o brônquio-fonte livre de seu suprimento sanguíneo principal. A importância do fluxo pulmonar para a cicatrização da área de anastomose, apesar de menos qualificada que o fluxo sistêmico, manifesta-se numa fase mais tardia. Conforme observou-se na revisão da literaturà. A rearterialização espontânea, após o reimplante pulmonar, inicia-se somente entre o $12^{\circ}$ e o $15^{\circ}$ dia de evolução e, solidifica-se em quatro semanas, através de vasos colaterais provenientes da circulação pulmonar (Rabinovich, 1972, Siegelman et al., 1977).

Os resultados provaram também que esse longo tempo de isquemia é bastante deletério para a cicatrização da anastomose brônquica, de modo que a revascularização precoce, seja de maneira direta, seja de maneira indireta, possa promover uma recirculação sanguínea no brônquio, minimizando as complicações aéreas instaladas nesses pacientes.

\section{Conclusões}

1 - A área desvascularizada e sem "proteção" da anastomose brônquica levou a ulceração da mucosa, porém sem formação de fístulas. 
2 - A proteção da anastomose brônquica com gordura mediastinal melhora a revascularização e cicatrização.

3 - Deve-se continuar estudando o assunto procurando mimetizar os fatores de agressão que interferem no processo cicatricial realizando-se o transplante propriamente dito e utilizando-se outros tecidos com capacidade angiogênicas.

\section{Abstract \\ Bronchial anastomose protection with pedicle autolog fat tissue. An experimental study in dogs, Canis familiaris}

The authors analised 16 mongrel dogs, of both sexes, with weight from 12 to $20 \mathrm{~kg}$, in good health conditions, divided in 2 groups. In the control group (I) had to anastomose protection and in the other group (II) a protective pedicle of mediastinal fat as an autolog tissue was used. All dogs were submitted to general volatil anesthesia. A valvuled circuit whit $\mathrm{CO}_{2}$ absorption was utilized for this purpose. The animals were manteined with a manually controled ventilation. A left lateral toracotomy was performed and the pleural cavity was reached through the 5th intercostal space. The bronchial artery was seccioned with a minimún peribronchial stripping and a followed by a transversal seccion of the main left bronchius in a medial distance between the carina and the lobules. The performance of a selective intobation permitted the maintainance of the sole right lung ventilation until the end of the anastomose. The group that had protection (II) had the mediastinic fat dissecated from the pericardic, manteined its nourishing pedicle and it was fixed in a flap from surounding the anastomose. A thoracorraphy was done per layer, and a sub-aquatic drainage was performed. The dog were submitted to euthanasia on the 15 th post operative day and the bronchial segments containing the anastomose were examined histologically. It was then concluded that the desvascularization of the bronchic anastomose is a factor of delay or impairmentt of the healing process, and that the mediastinal fat is sufficient to promove neovascularization in the anastomose area, and to promote an adquated healing process.

Key words: anastomose, bronchius, dogs

\section{Referências Bibliográficas}

ALLICAN, F., CAURILI, M., ISIN, EROL, HARDY, J.D. Surgical techinique of one-stage bilateral lung reimplantation in the dog. J. Thorac. Cardiovasc. Surg., v. 6, n. 6, p. 874-856, 1971.

ARAÚJO, E.D. Transplante do pulmão. Problemas técnicos e avaliação dos resultados imediatos. Rio de Janeiro, 1970. 85p. Tese (Livre Docência de Cirurgia Torácica) - Faculdade de Medicina - Universidade Federal do Rio de Janeiro.

BJORK, V.O. Suture material and techinique for bronchial closure and bronchial anastomose. J. Thorac. Surg., v. 32, n. 1, p. 22-27, 1956.

BREWER, L.A. Bronchopleural fistula: management. In: GRILLO, H.C., ESCHAPASE. H. International trendes in General Thoracic Surgery., W.B. Saunders, 1987 , v. 2, p. 398-406.

CAMARGO, J.J.P., ROCHA, M.G., OLIVEIRA, M.E.M., OLIVEIRA, J.C. Envolvimento da anastomose brônquica por gordura pericárdica do recptor e retalho do pericárdio do doador em transplante pulmonar. $J$. Pneum. Supl., v. 6, n. 1, p. 9-32, 1990.
COOPER, J.D. , PEARSON, F.G., PATTERSON, G.A., TOOD, T.J.R., GINBERG, R.J., GOLDBERG, M., DEMAJO, W.A.P. Techinique of succesful lung transplantation in humans. J. Thorac. Cardiovasc. Surg., v. 93, p. 173181,1987

DE PAOLA, D., DUARTE, F. PINSKKWAS. Agressão, Resposta à agressão. Mecanismos básicos de doenças. Rio de Janeiro, Ateneu, 1980, 385p

DERON, F., BARBIER, F., RINGOIR, S., ARNOLD, M. Ten month survival after lung homotransplantation in man. J. Thorac. Cardiovasc. Surg., v. 61, p. 835-846, 1971.

DODMAN, N.H., SEELER, D.C., NORMAN, W.M. General anaesthesia for small animal patients with respiratory insuficiency. Bristh Veterinary Journal, v. 143, p. 291-305, 1987.

ELLIS, H., GRINLA, J.H., EDWARDS, J. The bronchial arteries. I. Experimental oclusion. Surgery v. 30, n. 5, p. 810-827, 1951

FABER, L.P., JENSIK, R., KITTLE, F., Results of sleeve lobectomy for bronchogenic carcinoma in 101 patients. Ann. Thorac. Surg., v. 37, n. 4, p. 279-285, 1984.

FISCHER, A.B., KOLLMEIER, H. BODY, J.S., LINDE, L.M. Restoration of sistemic blood flow to the lung after division of bronchial arteries. J. Appl. Physiol., v. 29, n. 6, p. 839-846, 1970.

FUJIMURA, S., KOND, T., HANDA, M., YAMAUCHI, A., OKABE, T., SAITO, R., ICHINOSE, T., SHIRAISHI, Y., NAKADA, T. Histological assessment of bronchial anastomotic healing in canine lung transplantation. J. Thorac. Cardiovasc. Surg., v. 94, n. 3, p. 323-330, 1987.

GOLDBERG, M., LIMA, O., MORGAN, E., AYABE, H.A., LUK, S., FERDMAN, W.J., COOPER, J.D. A comparison between cyclosporin A and metylpredinisolone plus azathioprine on bronchial healing folowing lug transplantation. J. Thorac. Cardiovasc. Surg., v. 85, p. 821-826, 1983.

GRAEBER, M.G., COLLINS, J.J.H., DESHONG, J.L., MURRAY, G.F. Are suture better than staples for closing bronchi and pulmonary vessels. Ann. Thorac. Surg., v. 56, n. 6, p. 901-905, 1991

GRAHAM, E., SINGER, J.J. Succesful removal of an enterie lung for carcinoma of the bronchus. JAMA, v. 101, p. 1371, 1983.

JÚDICE, L.F., CORDEIRO, S.B., RAMOS, L.M., SANTINI, L.A.R. Traumatismo da traquéia Arq. Bras. Med. v. 59, n. 3, p. 149-152, 1985.

KIRK, A.J., CONACHER, L.D., CORRIS, P.A., GIBERT, T. Succesful surgical management of bronchial dehiscence after sing lung transplantation. Ann. Thorac. Surg., v. 49, p. 147-149, 1990

LIMA, O.A.S. Factors affecting bronchial healing in lung transplantation. Toronto, 1981. 215p. Thesis (Phd) - Toronto University.

Lo CICERO, J., MASSAD, M., MATANO, J., GREENE, R. Contribution of the bronchial circulation to lung preservation. J. Thorac. Cardiovasc. Surg., v. 101, n. 5, p. 807-815, 1991

MATHIESEN, D.J., GRILLO, H.C. Carinal ressection for bronchogenic carcinoma. J. Thorac. Cardiovasc. Surg., v. 102, p. 16-23, 1991.

MEDEIROS, M.J.Q., ALMEIDA, JR., DUARTE, J.M. Cicurgia da reimplantação pulmonar: estudo experimental. Acta. Cir. Bras., v. 6, n. 1, p. 8-20, 1991.

MELLO, R.F., SIQUEIRA, O.F. Anastomose brônquica. Rev. Bras., v. 6, n. 1 , p. 8-20, 1991

MILLS, N.L., BOYD, A.D., GHERANPONG, C., SPENCER, F.C. The significance of bronchial circulation in lung transplantation J. Thorac. Cardiovasc. Surg., v. 60, n. 6, p. 866-878, 1970.

NAEF, A.P. Chirugie Thoracique Ses pioners et tournants decisifis. Editions Medicine et Hygiene Geneve: Italy, 1988. 258 p.

NARUKE, T., YONEMA, T., OGAGTA, T., SUEMASU, K. Bronchoplastic producere for lung cancer. J. Thorac. Cardiovasc. Surg., v. 73, n. 6, p. 927-936, 1977.

NORMANDO JR, G.G. O emprego de tecidos pediculados na proteção do auto enxerto brônquico. Niterói, 1992. 106 p. Dissertação (Mestrado em Cirurgia Torácica) - Universidade Federal Fluminense.

PAUL, A., MARKEI, D., SHENNIB, H., KING, M., WILSON, J.A.S. Mucocoliary function in auto transplanted, allotransplanted, and sleeve resected lung. J. Thorac. Cardiovasc. Surg., v. 98, p. 532-538, 1989. 
PETERFFY, A., CALABRESSE, E. Mechanical and conventional manual sutures of the bronchial stump. Scand J. Cardiovasc. Surg., v. 13, p. 87-91, 1979

PINSKER, K.L., KOERNER, S.K., KAMHOLZ, S.I., HAGSTROM, J.W.C., GLIEDMAN, M.L., VEITH, F.J. Improved bronchial anastomose healing secondary to circulation by microsurgical techiniques. Surg. Forum, v. 319, p. 230-233, 1980.

RABINOVICH, J.J. Re-estabeleciment of bronchial arteries after experimental lung lobe autotransplantation in primets with extend susvival. J. Thorac. Cardiovasc. Surg., v. 64, n. 1, p. 119-126, 1972.

SIEGELMAN, S.S, HAGSTROM, J.W.C., KOERNER, S.K., VEITH, F.J Restoration of bronchial artery circulation after canine lung allotransplantation. J. Thorac. Cardiovasc. Surg., v. 73, n. 5, p. 792-795, 1977

STREVEY, I.E. Delayed repair of the ruptured bronchus J. Thorac. Cardiovasc.
Surg., v. 59, n. 5, p. 638-641, 1970

TEIXEIRA, J. Instrumentos originais em cirurgia cardiotorácica, R.C.B.C., v. 23, n. 4, p. 132-138, 1991.

TRUMMER, M.J., BERG, P. Lung transplantation. New York: Thomas, 1969. 565p. (Americ Lecture Series, 698)

VEITH, F.J., RICHARDS, K. Improved techinic for canine lung transplantation. Am. Surg., v. 171, n. 4, p. 553-558, 1970

VIRKULA, L., AEROLAS, S. Use of omental pedicle for treatment of bronchial fistula after lower lobectomy. Scand. J. Thorac. Cardiovasc. Surg., v. 9, p. 287-290, 1975.

WARREN, N.R. \& DUNPHY, J.E. Wound healing. In: DE WARREN, N.R., Surgery Philadelphia: London, 1969, p. 1-21.

WILLIANS, N.S., LEWIS, C.T. Bronchopleural fisula: a review of 86 cases. Br. J., v. 63, p. 520-529, 1989.

\section{VACINAS FORT DODGE. SEGURANÇA DE RESULTADOS NA DOSE CERTA.}

DURAMUNE DA,PP CvK/LCI: Vacina óctupla, em apenas $1 \mathrm{ml}$, que previne e protege contra as prncipai doenças que afetam os cães

Parvovirose, Coronavirose, Hepatite, ParaInfluenza, Cinomose,

Adenovirose e Leptospirose canicola e icterohaemorrhagie.
FEL-O-VAX PCT-R:

Vacina tríplice felina, acrescida de Raiva, em apenas $1 \mathrm{ml}$. A única feit exclusivamente com vírus mortos. Máxima segurança para gatos.

\section{ANNUMUNE:}

Vacina contra raiva de vírus morto, em $1 \mathrm{ml}$ para cães e gatos. Mais de 30 milhôes de doses administradas em todo o mundo.

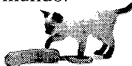

ERVIÇO DE ATENDIMENTO FORT DODGE/CYANAMID COM A GENTE 0800-212308
FORT DODGE

O novo padrão de referência. 